\title{
SMOS reveals the signature of Indian Ocean Dipole events
}

\author{
Fabien Durand ${ }^{1,{ }^{*}}$, Gaël Alory ${ }^{1}$, Raphaël Dussin ${ }^{2}$, Nicolas Reul $^{3}$
}

1 LEGOS, UMR 5566, CNRS-CNES-IRD-UPS, Université de Toulouse 3, 14 Avenue Edouard Belin, 31401, Toulouse, Cedex 09, France

2 LEGI, Domaine Universitaire, BP-53, 38041, Grenoble, Cedex 09, France

3 LOS, Ifremer, Centre Méditerranée, Zone Portuaire de Brégaillon, CS20 330, 83507, La Seyne-sur-Mer, Cedex, France

*: Corresponding author : Fabien Durand, email address : fabien.durand@ird.fr

\begin{abstract}
:
The tropical Indian Ocean experiences an interannual mode of climatic variability, known as the Indian Ocean Dipole (IOD). The signature of this variability in ocean salinity is hypothesized based on modeling and assimilation studies, on account of scanty observations. Soil Moisture and Ocean Salinity (SMOS) satellite has been designed to take up the challenge of sea surface salinity remote sensing. We show that SMOS data can be used to infer the pattern of salinity variability linked with the IOD events. The core of maximum variability is located in the central tropical basin, south of the equator. This region is anomalously salty during the 2010 negative IOD event, and anomalously fresh during the 2011 positive IOD event. The peak-to-peak anomaly exceeds one salinity unit, between late 2010 and late 2011. In conjunction with other observational datasets, SMOS data allow us to draw the salt budget of the area. It turns out that the horizontal advection is the main driver of salinity anomalies. This finding is confirmed by the analysis of the outputs of a numerical model. This study shows that the advent of SMOS makes it feasible the quantitative assessment of the mechanisms of ocean surface salinity variability in the tropical basins, at interannual timescales.
\end{abstract}

Keywords: SSS ; Indian Ocean Dipole ; SMOS ; ARGO ; ENSO 


\section{Introduction}

SMOS (Soil Moisture and Surface Salinity) satellite was successfully launched in November 2009, with two primary objectives: remotely sensing the moisture of the continental surfaces and the surface salinity of the oceans. For salinity, it is the first-of-its-kind spaceborne mission dedicated to this parameter. Surface salinity has been identified as one of the Essential Climate Variables (ECV) by Global Climate Observing System (GCOS) program (see www.wmo.int/pages/prog/gcos/). The nominal requirements for SMOS salinity retrieval was to achieve a 0.1 accuracy (in practical salinity scale), over time / space scales of 10-30 days / $200 \mathrm{~km}$ (Mecklenburg et al. 2008; Font et al. 2010). The actual quality of the SMOS data differs from one basin to the other (Reul et al. 2012; Boutin et al. 2012), as the processing of raw data is quite challenging. At least two full years of processed observations of the global sea surface salinity (SSS) field (2010 and 2011) are now available. It turns out that these two years were rich in climatic events. In particular there was a switch from El Niño conditions to La Niña conditions in the tropical Pacific in mid-2010, as well as a succession of a negative Indian Ocean Dipole (IOD) event (in 2010) and a positive IOD event (in 2011) in the Indian Ocean basin. The spatio-temporal coverage of SMOS data offers an unprecedented opportunity to examine the salinity signature of this kind of events. Figure 1 contrasts the SSS field in late 2010 and late 2011, as seen by SMOS, at global scale. The central-south equatorial Indian ocean strikingly stands out as the region with the most prominent anomalous pattern, with surface waters fresher in 2011 by about 1 unit as compared to 2010, over the area [70 ${ }^{\circ} \mathrm{E}$ $\left.95^{\circ} \mathrm{E}\right] \times\left[3^{\circ} \mathrm{S}-13^{\circ} \mathrm{S}\right]$. This pattern is actually the largest year-to-year anomaly captured by SMOS since its launch (Reul et al., 2013). This box will be hereafter referred to as Central Indian Ocean (CIO). The aim of the present study is twofold. First, we present an assessment of the realism of SMOS level-3 SSS product over this area. Then, we investigate the mechanisms responsible for this anomalous pattern. Section 2 presents the various datasets we use (SMOS SSS in particular, but also the other products used for validation and for the process study). Section 3 describes the SSS anomalous pattern in the CIO. Section 4 and 5 analyse the mechanisms responsible for this anomaly, from an observational and numerical perspective respectively. Section 6 concludes the paper.

\section{Data and methods}


SMOS (Soil Moisture and Ocean Salinity) is the European Space Agency (ESA)'s water mission (Font et al. 2010; Mecklenburg et al. 2012), an Earth Explorer Opportunity Mission belonging to its Living Planet Program. SMOS was launched in November 2009 and the technical approach developed to achieve adequate radiometric accuracy, as well as spatial and temporal resolution compromising between land and ocean science requirements, is polarimetric interferometric radiometry (Font et al. 2010) at L-band (frequency of $\sim 1.4 \mathrm{GHz}$ ). ESA produces so-called Level 2 SSS, or L2 products, which correspond to instantaneous SSS retrievals under the satellite swath. Accuracy of these instantaneous SSS retrievals is rather low ( 0.6-1.7 unit) and space-time averaging of the L2 products is needed (so-called Level 3 SSS) to decrease the noise level in the retrievals.

Here we used composite SSS level 3 products operationally generated by the Centre Aval de Traitement des Données SMOS (CATDS, http://www.catds.fr), which is the french ground segment for the SMOS data. These products were released in July 2012 and cover the January 2010-April 2012 period. This dataset has some limitations: SSS retrieved at less than $10^{\circ}$ from continents are possibly biased negatively by up to about -1 , SSS retrieved in the northern Atlantic and in the vicinity of Asian coasts (Arabian Sea and Bay of Bengal in particular) must be considered with caution due to radio frequency interferences, differences (up to 0.2 for SSS averaged over ocean basins) remain between SSS retrieved from ascending and descending orbits, and quality of retrieved salinity is poorer before June 2010 (Reul et al. 2012). Recently two studies (Subrahmanyam et al. 2012; Ratheesh et al. 2013) were specifically dedicated to the assessment of SMOS level 3 products over the tropical Indian Ocean sector. By comparing the spaceborne SSS data with in situ observations, both studies concluded that SMOS level 3 products are within the bounds of the specified accuracy requirements for the mission over the southern part of the tropical Indian Ocean (to the South of the Equator), whereas the performances are not satisfactory in the Northern Indian Ocean (both in the Arabian Sea and in the Bay of Bengal). Our region and period of interest in this study is out of the most critical areas. We used monthly $1^{\circ}$ resolution data combining ascending and descending orbits.

\section{2 in situ SSS dataset}


In order to validate the spaceborne SSS product, we worked out a gridded product, based on all available in situ observations we could find. ARGO profilers provide the bulk of the data. Typically, over the 2010-2011 period, about 20 such floats have been consistently roaming in our CIO box, each of them profiling at a period of 7 to 10 days. For each available profile, we considered the uppermost salinity datum situated in the $5 \mathrm{~m}-15 \mathrm{~m}$ layer as SSS (on condition that its ARGO delayed-mode quality flag is defined as "good or "probably good"). In addition, we considered salinity data measured by RAMA buoys (McPhaden et al. 2009). Six buoys have been episodically measuring salinity at $1 \mathrm{~m}$ depth over the $\mathrm{CIO}$ box (at $12^{\circ} \mathrm{S}-80^{\circ} \mathrm{E}, 12^{\circ} \mathrm{S}-93^{\circ} \mathrm{E}$, $4^{\circ} \mathrm{S}-80.5^{\circ} \mathrm{E}, 5^{\circ} \mathrm{S}-95^{\circ} \mathrm{E}, 8^{\circ} \mathrm{S}-80.5^{\circ} \mathrm{E}, 8^{\circ} \mathrm{S}-95^{\circ} \mathrm{E}$ ). Additionally, a merchant ship (M/S Lavender), equipped with a thermosalinograph continuously measuring the near-surface salinity, has been crossing the CIO box 7 times from March 2010 through September 2011 (typically once every 3 months). The thermosalinograph data went through a delayed mode quality control including comparison with climatology and correction with external water samples. All these data were gridded on a $1^{\circ} \times 1^{\circ} \times 1$ month regular grid, by taking the median of all individual observations falling in each grid point. This procedure is similar to that of de Boyer Montégut et al. (2004).

\subsection{Ancillary oceanographic datasets}

To assess the role of the atmospheric freshwater fluxes on the salinity variability retrieved by SMOS, we consider TMI spaceborne precipitation (monthly, $1 / 4^{\circ}$ resolution, available on ftp.ssmi.com/tmi) and OAFLUX (Yu et al. 2008) evaporation estimate (monthly, $1^{\circ}$ resolution, available on oaflux.whoi.edu). The role of oceanic advection is estimated with the satellitebased OSCAR surface current product (available at NOAA). This product is a combination of altimetry-derived geostrophic current and Ekman drift from scatterometer wind (Bonjean and Lagerloef 2002). In the present study, we used the $1^{\circ} \times 1^{\circ} \times 1$ month filtered version of OSCAR.

\subsection{Model run}

The model used here is the NEMO (Nucleus for European Modelling of the Ocean) ocean general circulation model (OGCM) described by Madec (2008). It solves the set of primitive equations where the tracers (temperature and salinity) and the horizontal component of 
velocity are prognostic variables and the vertical velocity is diagnosed through the continuity equation. The configuration we use in this study covers the entire globe, and has already been used by Hasson et al. (2012) for salinity studies. We use a Mercator grid, quasi-isotropic at these latitudes, with a resolution of $1 / 4^{\circ}$. On the vertical, the model resolves 75 levels, with 8 levels in the upper $10 \mathrm{~m}$. The timestep amounts to 16 minutes for all prognostic variables. Our simulation (ORCA025-L75) has been carried out as part of the Drakkar project (Drakkar group 2007). The sub-grid scale lateral processes are parameterized through a Laplacian diffusion acting along isopycnal surfaces, with a coefficient of $300 \mathrm{~m}^{2} . \mathrm{s}^{-1}$ for tracers. The vertical turbulent closure scheme is the TKE (Blanke and Delecluse 1993). The atmospheric forcing of the model was derived from three hourly ERA-interim reanalysis for the 1990-2011 period, with corrected radiative fluxes towards GEWEX satellite data as in the GLORYS2V2 reanalysis (Ferry et al. 2011). Note that there is no surface restoring term for salinity. The precipitation-minus-evaporation forcing flux was corrected a priori following the strategy of Vialard et al. (2002) (the model was first run with a relaxation of its SSS towards World Ocean Atlas SSS climatology; the monthly climatology of the relaxation term was then computed, and added as a correction to the atmospheric forcing applied in a second run). The simulation covers the 1990-2011 period, but we consider only the last two years (2010-2011) here. The model code, set-up and outputs are very similar to that used by Keerthi et al. (2012) and Nidheesh et al. (2012). These authors carried out a thorough validation of the realism of the model outputs in the tropical Indian Ocean, that is not repeated in the present paper.

\subsection{Mixed layer salinity budget}

To quantify the various processes driving SSS variability in the CIO, we will use the standard method of the mixed-layer salinity budget. Basically, from the law of salt conservation applied to the oceanic mixed layer, it is known that salinity of the mixed layer varies under the influence of freshwater exchanges with the atmosphere (evaporation and precipitation), horizontal advection by oceanic currents, and exchanges with the subsurface layers (vertical physics). This method has been used in a few prior studies examining salinity variability of the tropical Indian Ocean, based on observations (Rao and Sivakumar 2003) and numerical models (Thompson et al. 2006; Vinayachandran and Nanjundiah 2009). Here, we will calculate the salinity budget of the mixed layer in the CIO area, based successively on observations and on model outputs. 
For the observation-based budget, we will rely on the following equation:

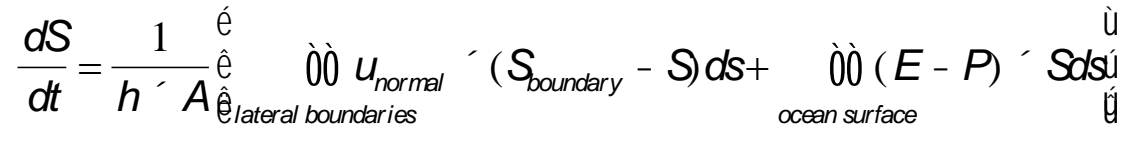

where $S$ is the mixed-layer salinity (averaged over the CIO domain), $h$ is the mixed-layer thickness (assumed constant, equal to $40 \mathrm{~m}$, based on the climatology of mixed-layer depth of de Boyer Montégut et al. 2004), $A$ is the horizontal area of the CIO domain, $u_{\text {normal }}$ is the horizontal current considered in the direction normal to the CIO boundaries (viz. zonal component for the East and West boundaries, and meridional component for the North and South boundaries), considered positive when entering the CIO box; $S_{\text {boundary }}$ is the salinity at the boundary of the domain; $E$ is the evaporation flux at air-sea interface, $P$ is the precipitation flux. The first term of right-hand-side of (1) is a two-dimensional integral computed along the vertical surfaces of the four boundaries of the CIO box. The second term is a two-dimensional integral computed over the air-sea interface of the CIO box. This equation basically neglects the space and time dependencies of the mixed layer depth over the domain; it also assumes that the vertical exchanges of salt between the mixed layer and the oceanic subsurface are of second order. This is clearly a limitation of the approach, as we shall see in Section 4. On the other hand, the recently available SMOS SSS data, used jointly with previously available satellite precipitation and current products, make a dataset combination of unprecedented space-time coverage and homogeneity for computation of surface processes.

As a complement to the observed SSS budget, we will also analyse the numerical model outputs (Section 5). Hasson et al. (2012) followed an identical approach, using the same model simulation but in a different geographical context. The reader is referred to that paper for a complete description of the methodology (including the salinity budget equation solved by the model), and for past references using it. Basically, the fundamental difference of this method compared to the simple approach of Equation (1) is that vertical exchanges are explicitly taken into account in the model computation of salinity budget. These exchanges consist of vertical advection of salinity through the base of the mixed-layer, entrainment at the time-varying mixed layer depth, and turbulent diffusion through the base of the mixed layer.

\section{Observed SSS variability in the CIO}




\subsection{Seasonal cycle of SSS}

Figure 2 shows the seasonal evolution of SSS averaged over the CIO domain inferred from several sources, including World Ocean Atlas 2005 (henceforth WOA05) climatology (Antonov et al. 2006), 2010-2011 blended in situ dataset and SMOS satellite estimates. WOA05 SSS climatology exhibits strong seasonal variations within the considered region, with a freshening of about 0.6 from July (SSS=34.85) to January (SSS=34.25), a roughly stable SSS from January to May, followed by a saltening of 0.5 from May (SSS=34.35) to July (SSS=34.85). Little is known about the mechanisms of this seasonal variability. Nevertheless, the CIO region is located on the western edge of the Indo-Pacific fresh pool, and subject to intense seasonal variability of both precipitation and oceanic currents. Precipitation is strong throughout the year at the eastern edge of the tropical Indian Ocean, but the area of heavy precipitation episodically migrates westward towards the CIO in boreal fall (e.g. Masson et al. 2002). The eastern edge of the basin shows low SSS (below 34.0) throughout the year (Masson et al. 2002). In addition, the surface currents also show a marked variability with the CIO box located on the pathway of the South Equatorial Current (SEC). Shenoi et al. (1999) reported that the SEC accelerates westward during summer, and slows down during winter. Hence, the seasonal variability of both precipitation and horizontal circulation has the potential to induce a freshening of the surface waters in summer-fall within CIO box.

\subsection{0: an anomalous year for SSS}

Figure 2 reveals a significantly different seasonal evolution of SSS between the climatology and SMOS data acquired during the January 2010 to April 2012 period. During the first half of 2010, SMOS SSS shows an evolution very similar to WOA05, with a saltening from May (value 34.2 ) to July (value 34.8). From this date, SMOS salinity completely diverges from WOA05, with values remaining consistently high (between 34.65 and 34.9) until July 2011. Subsequently (August 2011 - April 2012), SMOS SSS shows again a rather good consistency with WOA05. This period exhibits a succession of two very contrasted phases in the SMOS dataset, with close-to-normal seasonal evolution before July 2010 as well as after July 2011, and very abnormal conditions in the intervening period (July 2010 through July 2011). 
Figure 2 illustrates the validity of the SMOS averaged SSS trend over CIO, which compares well against the blended in situ product presented in Section 2.2. It is seen that the in situ product is in line with the spaceborne product, with little departure from W0A05 before July 2010 and after July 2011, and a salty anomaly in between. The agreement with SMOS is typically better than 0.1 in absolute values, with a maximum difference of 0.25 (SMOS being fresher than the in situ blend) in September 2010. The good performance of SMOS products in this region is probably associated with the high sea surface temperatures, which maximize the sensitivity of spaceborne measurements to SSS. Additionally, this region is located sufficiently far away from the surrounding continents as well as from the known sources of radio-frequency interferences (prominently located in central Asia, for the Indian Ocean sector). We are confident in using SMOS SSS to further investigate the mechanism of the 2010-2011 year-to-year variability.

\subsection{Large-scale patterns of SSS driving terms: 2010 vs 2011}

Figure 3 illustrates the large-scale interannual variability of SSS and of its various driving terms, for the two contrasting periods (summer-fall 2010 and summer-fall 2011). During both periods, the satellite SSS product accurately detected the two known surface water masses of the tropical Indian Ocean, with salty waters (SSS greater than 34.5) in the Arabian Sea, central equatorial basin, and southern subtropical basin, and fresher waters (SSS lower than 34.5) in the Bay of Bengal and at the eastern edge of the equatorial basin (Figure 3a). However, the frontal zone separating those two water masses (delineated by the 34.5 isohaline) has a completely different position from one year to the other: in summer 2010 the front is located along the eastern edge of the CIO box (around $90^{\circ} \mathrm{E}$ ) whereas one year later it lies in the central part of $\mathrm{CIO}$ box, tilted in the northwest-southeast direction, around $85^{\circ} \mathrm{E}$. Hence in summer 2010, the CIO box essentially shows salty surface waters (SSS in excess of 34.5) whereas about half of the domain is covered with waters fresher than 34.5 in summer 2011. As illustrated by Figure 3a, this contrast in SSS is associated with drastic changes in the surface circulation. In 2010, the surface current essentially flows clockwise along the isohalines, eastward in the northern part of CIO, southward in the eastern part, and westward in the southern part of the area. Contrarily, in 2011 the surface current is essentially westward, perpendicular to the isohalines, hereby conducive to a massive freshening of the CIO box. 
In addition to the horizontal current, Figure 3 also shows the interannual variablity of two potential drivers of SSS variability in that central Indian Ocean region: precipitation (Figure 3b) and evaporation (Figure 3c). During both summer 2010 and summer 2011, precipitation is strong (in excess of $4 \mathrm{~mm}$ /day) throughout the eastern equatorial basin, in the South-eastern Arabian Sea and in the South-Eastern Bay of Bengal. A striking contrast appears off the coast of Sumatra: while it is very rainy in 2010 (with precipitation values greater than $8 \mathrm{~mm} /$ day in a region extending westward from the island up to the eastern half of CIO domain), it is basically dry in 2011. Then, the rainy pattern seems to have shifted about 2000 $\mathrm{km}$ westward, right over the central and western part of CIO box (and further, west of it, until $60^{\circ} \mathrm{E}$ ). At this stage, however, it is not clear whether local precipitation drives the SSS contrast in the studied region: in 2010, it shows stronger maxima than in 2011 over the CIO box, but it concerns only the eastern half of the domain, whereas in 2011 the rainy pattern is less pronounced but wider (covering the central and western part of the box). Evaporation (Figure 3c) is not very different during the two periods, with the CIO box sitting at the northern edge of the area of strong evaporation of the southern subtropical Indian Ocean (values greater than $5 \mathrm{~mm} /$ day).

Both the equatorial current reversal (Figure 3a) and the precipitation westward shift (Figure 3b) from 2010 to 2011 reflect known patterns of Indian Ocean Dipole (IOD) variability and are consistent with the succession of a negative and positive phase. Figure 2 shows the evolution of Dipole Mode Index (as defined by Saji et al 1999). This index is based on a difference of SST anomalies between two boxes located in the western and eastern equatorial Indian ocean; an IOD event is said to take place whenever this difference is greater than half the standard deviation of the index, during at least 3 months. On Figure 2, the Dipole Mode Index is computed from NOAA OI SST v2 (taken from www.jamstec.go.jp/frcgc/research/d1/iod). 2010 was a negative IOD event, and 2011 was a positive IOD event. The precipitation field illustrates the canonical pattern of IOD, as defined by Reverdin et al. (1986) and Webster et al. (1999), with convection occurring off Indonesia during normal years or negative IOD years, and shifting westward to the central and western Indian Ocean during positive IOD years. However, it is hard to say that this precipitation contrast (between 2010 and 2011) is conducive to the SSS contrast seen in Figures 1 and 2, as in both years the CIO box catches a significant part of the precipitation core. The contrast in horizontal current between 2010 and 2011 echoes the contrasting situation during fall 1996 (negative IOD) and fall 1997 (positive IOD) reported by Thompson et al. (2006). Jensen 
(2007) also found that the horizontal current of his model is anomalously westward over the CIO, during a positive IOD year.

\section{Salt budget in the CIO: an observational tentative}

As clearly illustrated by Figure 2, the most contrasted periods between 2010 and 2011 are seen in the second half of each year: in 2011 the CIO SSS drops during this season (consistently with the climatology), whereas in 2010 it remains close to the July value. This results in the strong year-to-year anomaly in December seen in Figure 1. In this section, we further investigate the potential processes responsible for such a different behaviour during the second half of each year. To that aim, we integrated Equation (1) in time, during two 6month long periods, beginning in July 2010 and July 2011. To by-pass the long-term mean balance between the various terms (responsible for the long-term average SSS, which is not the focus of the present study), we integrated equation (1) considering the anomalies of the two terms as regards to their long-term (2004-2011) average. We used SMOS SSS, OSCAR currents, TMI precipitation, and OAFLUX evaporation. Figure 4 presents the results of these two integrations. It is seen that this simple diagnostic model yields completely different results in 2010 as compared to 2011, with a saltening of 0.3 (from 34.8 to 35.1) from July to December 2010, and a freshening of 0.5 (from 34.8 to 34.3) from July to December 2011. Further, it is seen that this simple model allows reproducing the observed salinity evolution (black curve) during these two periods, though with a better agreement in 2011 as compared to 2010. In 2010, the model generates a positive drift of the diagnosed salinity, for a reason discussed in next section. Figure 4 provides the contribution of each of the two terms of equation (1) (horizontal salt advection and air-sea freshwater exchanges) to the total SSS evolution. Horizontal advection is further splitted into its zonal and meridional components. It is seen that the air-sea fluxes (evaporation minus precipitation) do not explain the observed contrast between 2010 and 2011: indeed, they induce a slight freshening of about 0.1 in 2010, and a slight saltening of less than 0.2 in 2011, contrary to the observed total change in both years. On the other hand, horizontal advection appears as a good candidate to explain the observed contrast: it induces a 0.4 saltening in 2010, and a 0.5 freshening in 2011 . We can see that both zonal and meridional advection equally contribute to the total advection in 2010, while zonal advection has a larger contribution than meridional advection to the freshening in 2011. 
An interesting characteristic of our simple diagnostic model is that it relies only on observed data (for salinity, currents, freshwater fluxes and mixed-layer depth). At this stage, however, we are not in a position to conclude that the CIO SSS behaves differently in 2010 and 2011 as a result of different horizontal transports of salt. Indeed, two limitations of the diagnostic model have to be kept in mind. First, it reproduces accurately the observed SSS change in 2011 only, and shows a salty trend building up in the first 3 months of integration in 2010. This is certainly linked to a missing process in Equation (1), which actually has a nonnegligible contribution to the SSS balance. Second, it is known that carrying out a SSS budget from monthly datasets in a large-scale tropical domain, while possibly explaining most of seasonal variability (Da-Allada et al. 2013) can be misleading. Indeed, the contribution of intra-monthly variability (in particular of advective fluxes) is potentially high (Hasson et al. 2012). This motivated us to carry out the same budget, based on the numerical model outputs.

\section{Numerical modeling of the CIO SSS}

In this section, we investigate the sensitivity of the CIO SSS budget, using the OGCM. Our first step was to validate the model. As discussed in Section 2, the model has been previously found to reproduce realistically the known surface circulation of tropical Indian Ocean, as well as the seasonal variability of upper ocean temperature and salinity (Keerthi et al. 2012; Nidheesh et al. 2012). In the previous section, we identified SSS as well as surface currents as the key parameters of the observed variability during the two contrasted periods (2010 and 2011). Here we focus specifically on the validation of these key-parameters. Figure 5 shows the model equivalent of Figure 3a. It is seen that the agreement between modeled and observed fields is remarkable, for SSS as well as for surface currents. The model successfully reproduces the two observed water masses, and the 34.5 isohaline appears as a good proxy of the front separating them, just like in SMOS observed field. In summer 2010, the salinity front simulated by the model is located at the eastern edge of CIO box, and the surface current flows clockwise in the box, roughly parallel to the isohalines. In summer 2011, the front has migrated to the central CIO, in association with a westward surface current. Just like for the observed current, the change in the modeled surface current pattern also echoes the IODrelated variability simulated by the models of Thompson et al. (2006) and Jensen (2007). Figure 6 shows the box-average evolution of model SSS (thick black line). It is very consistent with the SMOS observed SSS (dotted black line), with two maxima in summer 2010 and 
summer 2011, a stable SSS throughout the second half of 2010 and a sharp drop during the second half of 2011. One difference between model and observed SSS is seen during the first half of 2011, with the model simulating a 0.4 freshening (January-April) followed by a 0.4 saltening (April-June) whereas the observed field shows an evolution of half lesser amplitude over this period. The reason for this is not clear. We did not attempt to analyze the model outputs during this period, in consequence. Also, we notice a fresh (about 0.2-0.3) bias in the model, throughout the 2010-2011 period. This small bias might be linked to the imperfect flux correction strategy used to correct the evaporation-precipitation forcing field (see Section 2.4).

The mixed-layer salinity budget is computed online, at the model time step (16 minutes), using all the model fields. In particular, it is computed over the time-varying thickness of the mixed-layer. It is thus accurately closed (Vialard et al. 2002). Similarly with the observed SSS budget of Section 4, we carried out two 6-month long temporal integrations of the anomalies of model tendencies, one beginning on July $1^{\text {st }} 2010$, and another beginning on July $1^{\text {st }} 2011$. In the model, the combined effect of horizontal transports and oceanatmosphere freshwater fluxes is in line with the observation-based salinity budget (Figure 4). We can see that these processes induce a completely different SSS evolution in 2010 (saltening of about 0.4 from July to December 2010) and in 2011 (freshening of 0.5 from July to December 2011). The model also confirms that this contrasted evolution is mainly due to the horizontal transport, as it generates a 0.3 saltening from July to December 2010, versus a 0.7 freshening from July to December 2011. However, the detailed contribution of zonal and meridional advection to the total horizontal transport is different from the observed counterparts, with a zonal component in 2010 inducing a 0.3 SSS drop whereas the observed estimate amounts to a 0.1 saltening. This is not inconsistent as the formulation for the observation-based salt budget only takes into account external processes, while the formulation for the model-based budget (spatial integration of the local advection tendencies) includes both external and internal processes (Lee et al. 2004). This result suggests that significant salt redistribution occurs in 2010 within the CIO box. The contribution of freshwater fluxes to SSS evolution is also not exactly similar to the observed quantity, particularly so in 2011 when the freshwater fluxes in the model induce a 0.3 SSS rise, double to the contribution diagnosed in Section 4. One consistent feature of the two budgets lies in the departure between the SSS evolution (black curve) and the combined contribution of horizontal transport and freshwater forcing fluxes (red curves). In the OGCM, this occurs in 
2010 as well as in 2011, with a positive drift of SSS driven by these two processes as compared to the actual (total) SSS evolution. This is simply explained by the contribution of the vertical physics (exchanges with the underlying waters) that is not accounted for in the simple diagnostic model of Section 4: during both 2010 and 2011 integrations, the vertical exchanges induce a 0.3 freshening of SSS. In other words, the vertical exchanges compensate the 0.3 saltening effect of the combined horizontal advection and freshwater fluxes in 2010, and doubles the 0.3 freshening effect of the horizontal transport and freshwater fluxes in 2011. When adding up the contribution of the three processes in the model (horizontal transport, freshwater fluxes and vertical exchanges), we obtain a SSS evolution almost identical to the total SSS evolution (not shown), which validates our numerical method. The magnitude of the contribution of vertical physics to SSS evolution in the numerical model suggests that this process is an important factor of the SSS balance of the CIO, which prevented a closure of the budget in the simple diagnostic model of Section 4 in 2010.

\section{Discussion}

In this paper, we reported the signature of IOD events on SSS, as seen by SMOS satellite during the recent period (2010-2011). The Central Indian Ocean shows strong anomalous patterns, with a salty anomaly during the strong negative IOD of 2010, and a fresh anomaly during the positive IOD of 2011. The unprecedented space-time coverage of SMOS data allowed us to identify the forcing mechanisms of these anomalies. We could conclude that the horizontal transports are the main driver of this contrasted situation: in fall 2011, the freshwaters of the eastern equatorial basin are transported westward (into the CIO), whereas in fall 2010 they remain in the far-eastern basin. Very few studies have been published so far on the relationship between IOD and SSS in the Indian Ocean, most likely because of the scarcity of available salinity observations in the pre-SMOS and pre-Aquarius sensors era. Thompson et al. (2006) carried out a multidecadal OGCM simulation and reported a strong signature of IOD variability in CIO SSS, with typically a 0.4 difference between positive IOD years and negative IOD years around $\left(85^{\circ} \mathrm{E}, 7^{\circ} \mathrm{S}\right)$, in December (positive IOD yielding negative SSS anomaly, and vice-versa). Their pattern of variability is in line with our own findings, although the magnitude they report is about half what we found in the 2010-2011 case. This may be linked to the fact that they use a model where SSS is rather strongly relaxed to seasonal climatology. The main focus of their study was in a region situated to the north of the equator $\left(80^{\circ} \mathrm{E}-90^{\circ} \mathrm{E}\right.$, 
$0-5^{\circ} \mathrm{N}$ ), north of our CIO domain. However, based on a composite analysis, they suggested that anomalies of horizontal current are responsible for the occurrence of SSS anomalies in the $\mathrm{CIO}$, with anomalous westward-flowing current bringing low salinity from the South-Eastern Bay of Bengal and eastern equatorial basin into the CIO during positive IOD events, and viceversa during negative IOD events. Vinayachandran and Nanjundiah (2009) investigated the SSS variability of the tropical Indian Ocean, based on a coupled ocean-atmosphere simulation. Their model simulated a SSS variability of about the same magnitude as the forced model of Thompson et al. (2006). Their model also suggested that, in this area, SSS variability is mainly driven by the variability of horizontal salt advection, and the year-to-year fluctuations are primarily seen in boreal fall. In the present study we confirm this finding with our two SSS budget computations. Our quantitative budgets are hard to relate to that of Vinayachandran and Nanjundiah (2009) though, as they focus only on the positive IOD events in their analysis, and our period (2010-2011) is more characterized by the strong SSS anomalies seen during the negative IOD event of 2010. Based on SODA reanalysis, Grunseich et al. (2011) also suggested that the CIO is a region of highly variable SSS during IOD events, with positive anomalies during negative events and vice-versa. They also hypothesized that the horizontal circulation is anomalously eastward (westward) over the CIO, during negative (positive) IOD events. They investigated the influence of co-occuring El Niño / La Niña events and IOD events of SSS variability in the Indian Ocean. They suggested that El Niño events (La Niña events) tend to reinforce the SSS anomalies seen in the Northern Indian Ocean during positive IOD events (negative IOD events). The influence of ENSO variability on the southern part of the equatorial Indian ocean was weak, according to these authors. In 2010, we have the classical co-occurence of a negative IOD event with a La Niña event. In 2011, in contrast, we have the very infrequent co-occurence of a positive IOD event with a La Niña event. We have seen that there is a marked asymmetry between the two years in the magnitude of SSS anomalies in the CIO, with a very salty pattern in 2010 and a moderately fresh pattern in 2011 . From our results, it is not clear whether the exceptional co-occurence of positive IOD with La Niña in 2011 has a specific role in the modest amplitude of the SSS anomaly generated. A systematic assessment of this issue should be done, based on long numerical simulations and/or reanalyses.

Basically, our own conclusions are in line with the three studies of Thompson et al. (2006), Vinayachandran and Nanjundiah (2009) and Grunseich et al. (2011). Further, we provide quantitative evidence of the processes responsible for the very anomalous SSS 
pattern observed during the 2010 negative IOD. From Figure 2, it is seen that the SSS peaks lag behind the Dipole Mode Index peaks by 2 months in 2010 and about 4 months in 2011. Saji et al. (1999) suggested that during an IOD event, the horizontal current varies simultaneously to the Dipole Mode Index. Given the typical displacement of the SSS front in CIO box during an IOD event (about $15^{\circ}$ in longitude), and the typical magnitude of the

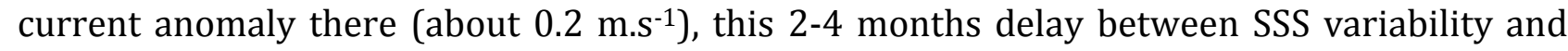
Dipole Mode Index evolution can be simply seen as the advective timescale of the SSS front through the CIO.

Clearly, the advent of SSS remote sensing opened a bright research opportunity, by allowing a continuous monitoring of SSS as well as SSS horizontal advective fluxes. The capability of SMOS to monitor the seasonal variability of SSS in the tropical Pacific Ocean was already proved (e.g. Alory et al. 2012). Here we demonstrate the unique utility of SMOS for the investigation of interannual events in the Indian Ocean. The vertical exchanges of salinity between the surface and subsurface waters, still, have to be assessed via numerical models, and their validation against observations is challenging. Thus we advocate for a synergistic use of remote sensing and numerical modelling, in order to infer quantitatively the mechanisms of SSS variability. Given the known implications of SSS anomalies on the upperocean stratification in the eastern and central tropical Indian Ocean (Masson et al. 2002, 2003, 2004), and their potential impact on air-sea interactions and climate variability there, we believe the present study opens interesting research perspectives.

Acknowledgements Thermosalinograph data were collected and processed by the French SSS Observation Service (www.legos.obs-mip.fr/observations/sss). CNES partly funded these activities in the frame of the Centre Aval de Traitement des Données SMOS (CATDS) and of the SMOS TOSCA projects. The numerical model simulation was produced as part of the DRAKKAR project; we are grateful to Jean-Marc Molines and Bernard Barnier for their contribution. We are thankful to Thierry Delcroix and Clément de Boyer Montégut for fruitful discussions.

\section{References}


Alory G, Maes C, Delcroix T, Reul N, Illig S (2012) Seasonal dynamics of sea surface salinity off Panama: The far Eastern Pacific Fresh Pool, J Geophys Res, 117, C04028. doi:10.1029/2011JC007802.

Antonov J I, Locarnini R A, Boyer T P, Mishonov A V, Garcia H E (2006) World Ocean Atlas 2005, Volume 2: Salinity. S. Levitus, Ed. NOAA Atlas NESDIS 62, U.S. Government Printing Office, Washington, D.C., 182 pp.

Blanke B, Delecluse P (1993) Variability of the tropical Atlantic Ocean simulated by a General Circulation Model with 2 different mixed layer physics. J Phys Oceanogr 23(7):13631388

Bonjean F, Lagerloef G S E (2002) Diagnostic Model and Analysis of the Surface Currents in the Tropical Pacific Ocean. J Phys Oceanogr 32(10):2938-2954.

Boutin J, Martin N, Yin X, Reul N, Spurgeon P (2012) First Assessment of SMOS Data Over Open Ocean: Part II-Sea Surface Salinity. IEEE Transactions on Geoscience and Remote Sensing, 50(5), Part 1:1662-1675.

de Boyer Montégut C, Madec G, Fischer A S, Lazar A, Iudicone D (2004) Mixed layer depth over the global ocean: an examination of profile data and a profile-based climatology. J Geophys Res 109, C12003, doi:10.1029/2004JC002378.

Da-Allada C Y, Alory G, du Penhoat Y, Kestenare E, Durand F, Hounkonnou N (2013) Seasonal mixed-layer salinity balance in the tropical Atlantic Ocean: Mean state and seasonal cycle. J Geophys Res, doi:10.1029/2012JC008357.

Drakkar Group (2007) Eddy-permitting Ocean Circulation Hindcasts of past decades. CLIVAR Exchanges 42, 12(3), 8-10.

Ferry N, Parent L, Garric G, Drevillon M, Desportes C, Bricaut C, Hernandez F (2011) Scientific validation report (ScVR) for V1 reprocessed analysis and reanalysis: GLORYS2V1. MyOcean FP7-SPACE-2007-1 project, report MYO-WP04-ScCV-rea-MERCATOR_V1Rep

Font J, Camps A, Borges A, Martín-Neira M, Boutin J, Reul N, Kerr Y H, Hahne A, Mecklenburg S (2010) SMOS: The Challenging Sea Surface Salinity Measurement from Space. Proceedings of the IEEE , 98(5):649-665.

Grunseich G, Subrahmanyam B, Murty VSN, Giese BS (2011) Sea surface salinity variability during the Indian Ocean Dipole and ENSO events in the tropical Indian Ocean. J Geophys Res, 116, C11013, doi:10.1029/2011JC007456. 
Hasson A, Delcroix T, Dussin R (2013) An assessment of the mixed layer salinity budget in the tropical Pacific Ocean. Observations and modelling (1990-2009). Ocean Dynamics, doi:10.1007/s10236-013-0596-2.

Jensen T G (2007) Wind-driven response of the northern Indian Ocean to climate extremes. J Clim, 20, 2978-2993, doi:10.1175/JCLI4150.1.

Keerthi M G, Lengaigne M, Vialard J, de Boyer Montégut C, Muraleedharan P M (2012) Interannual variability of the Tropical Indian Ocean mixed layer depth. Clim Dyn 40: 743-759.

Lee T, Fukumori I, Tang B (2004) Temperature advection: Internal versus external processes. J Phys Oceanogr 34:1936-1944.

Madec G (2008) NEMO reference manual, ocean dynamics component. Note du pôle de modélisation, IPSL, France ํํ27 ISSN N²1288-1619.

Masson S, Delecluse P, Boulanger J P, Menkes C (2002) A model study of the seasonal variability and formation mechanisms of barrier layer in the eastern equatorial Indian Ocean. J Geophys Res 107, 8017, doi:10.1029/2001JC000,832.

Masson S, Menkes C, Delecluse P, Boulanger J P (2003) Impacts of the salinity on the eastern Indian Ocean during the termination of the fall Wyrtki Jet. J Geophys Res 108, 3067, doi:10.1029/2001JC000,833.

Masson S, Boulanger J P, Menkes C, Delecluse P, Yamagata T (2004) Impact of salinity on the 1997 Indian Ocean Dipole event in a numerical experiment. J Geophys Res 109, C02002, doi:10.1029/2003JC001807.

Mecklenburg S, Kerr Y, Font J, Hahne A. (2008) The Soil Moisture and Ocean Salinity (SMOS) Mission - An overview. Geophysical Research Abstracts, Vol. 10.

Mecklenburg S., Drusch M, Kerr Y H, Font J, Martin-Neira M, Delwart S, Buenadicha G, Reul N, Daganzo-Eusebio E, Oliva R, Crapolicchio R (2012) ESA's Soil Moisture and Ocean Salinity Mission: Mission Performance and Operations. IEEE Transactions on Geoscience and Remote Sensing 50(5), Part 1:1354-1366.

McPhaden M J, Meyers G, Ando K, Masumoto Y, Murty V S N, Ravichandran M, Syamsudin F, Vialard J, Yu L, Yu W (2009) RAMA: The Research Moored Array for African-AsianAustralian Monsoon Analysis and Prediction. Bull Am Meteorol Soc 90:459-480.

Nidheesh A G, Lengaigne M, Vialard J, Unnikrishnan A S, Dayan H (2012) Decadal and longterm sea level variability in the tropical Indo-Pacific Ocean. Clim Dyn. doi 10.1007/s00382-012-1463-4. 
Rao R R, Sivakumar R (2003) Seasonal variability of sea surface salinity and salt budget of the mixed layer of the north Indian Ocean. J Geophys Res 108, 3009. doi:10.1029/2001JC000907

Ratheesh, S., Mankad B, Basu S, Kumar R, Sharma R (2013), Assessment of Satellite-Derived Sea Surface Salinity in the Indian Ocean. IEEE Geoscience and Remote Sensing Letters 10(3), 428-431, doi 10.1109/LGRS.2012.2207943.

Reul N, Tenerelli J, Boutin J, Chapron B, Paul F, Brion E, Gaillard F, Archer 0 (2012) Overview of the First SMOS Sea Surface Salinity Products. Part I: Quality Assessment for the Second Half of 2010. IEEE Transactions on Geoscience and Remote Sensing 50(5), Part 1:1636-1647.

Reul N, Fournier S, Boutin J, Hernandez O, Maes C, Chapron B, Alory G, Quilfen Y, Tenerelli J, Morisset S, Kerr Y, Mecklenburg S, Delwart S (2013) Sea Surface Salinity Observations from Space with the SMOS Satellite: A New Means to Monitor the Marine Branch of the Water Cycle. Surv Geophys, doi 10.1007/s10712-013-9244-0.

Reverdin G, Cadet D L, Gutzler D (1986) Interannual displacements of convection and surface circulation over the equatorial Indian Ocean. QJRMS 112(471):43-67.

Saji N H, Goswami B N, Vinayachandran P N, Yamagata T (1999) A dipole mode in the tropical Indian Ocean. Nature 401:360-363.

Shenoi S S C, Saji P K, Almeida A M (1999) Near-surface circulation and kinetic energy in the tropical Indian Ocean derived from Lagrangian drifters. J Mar Res 57(6) 885-907.

Subrahmanyam B, Grunseich G, Nyadjro E S (2012), Preliminary SMOS Salinity Measurements and Validation in the Indian Ocean. IEEE Transactions on Geoscience and Remote Sensing, doi 10.1109/TGRS.2012.2199122.

Thompson B, Gnanaseelan C, Salvekar P S (2006) Variability in the Indian Ocean circulation and salinity and its impact on SST anomalies during dipole events. J Mar Res 64:853880. doi:10.1357/002224006779698350.

Vialard J, Delecluse P, Menkes C (2002) A modeling study of salinity variability and its effects in the tropical Pacific Ocean during the 1993-1999 period. J Geophys Res Oceans 107(C12). doi:10.1029/2000jc000758.

Vinayachandran P N, Nanjundiah R S (2009) Indian Ocean sea surface salinity variations in a coupled model. Clim Dyn 33:245-263. doi:10.1007/s00382-008-0511-6. 
Webster P J, Moore A M, Loschnigg J P, Leben R R (1999) Coupled ocean-atmosphere dynamics in the Indian Ocean during 1997-98. Nature 401:356-360. doi:10.1038/43848.

Yu L, Jin X, Weller R A (2008) Multidecade Global Flux Datasets from the Objectively Analyzed Air-sea Fluxes (OAFlux) Project: Latent and sensible heat fluxes, ocean evaporation, and related surface meteorological variables. Woods Hole Oceanographic Institution, OAFlux Project Technical Report. OA-2008-01, 64pp. Woods Hole. Massachusetts. 


\section{Figures}

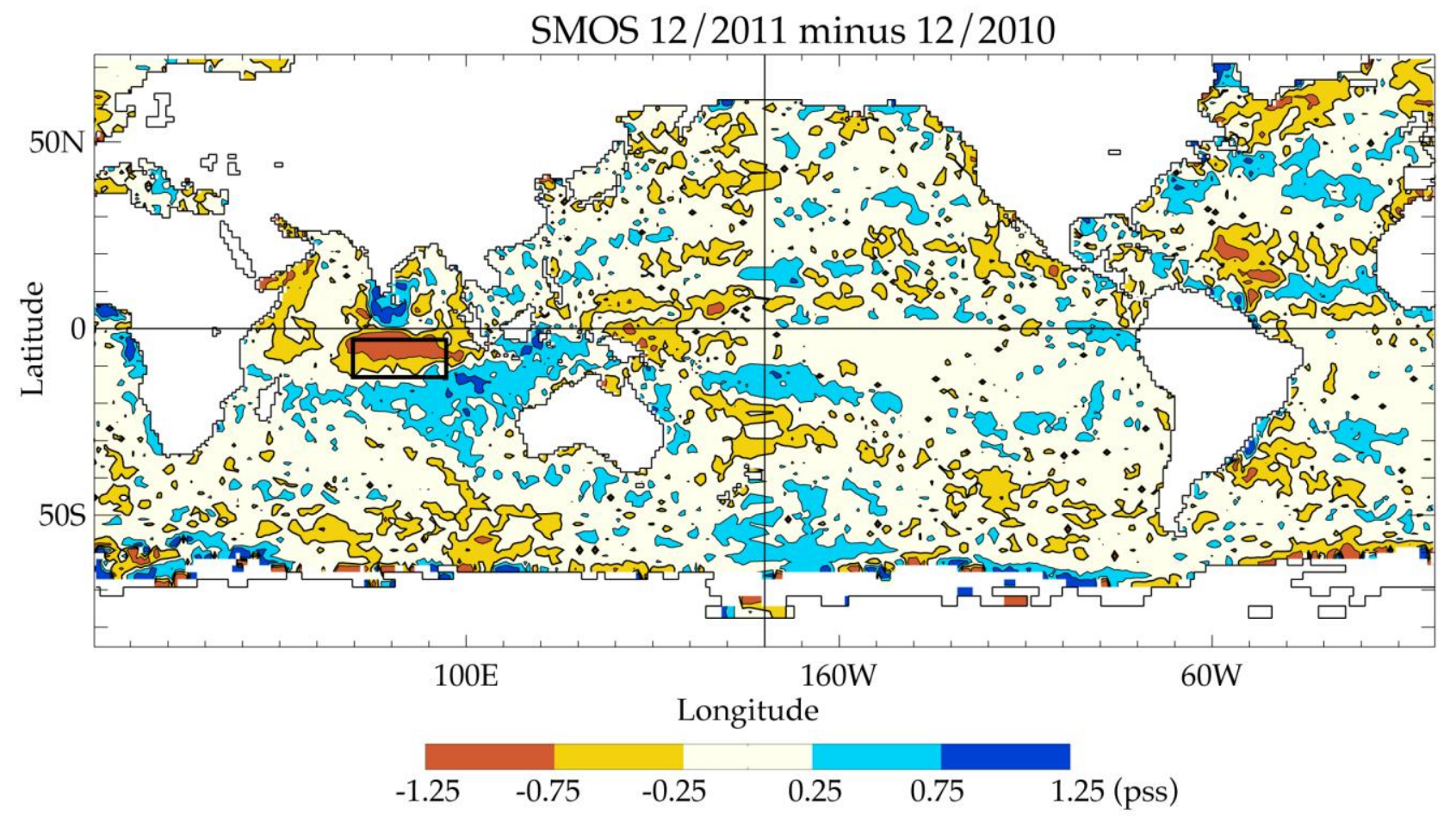

Figure 1. SMOS SSS difference between December 2011 and December 2010. Isocontours are every 0.5. Negative values indicate a salinity lower in 2011 than in 2010. The black box delineates the $\mathrm{CIO}$ region $\left(\left[70^{\circ} \mathrm{E}-95^{\circ} \mathrm{E}\right] \times\left[13^{\circ} \mathrm{S}-3^{\circ} \mathrm{S}\right]\right)$ used for subsequent analyses.

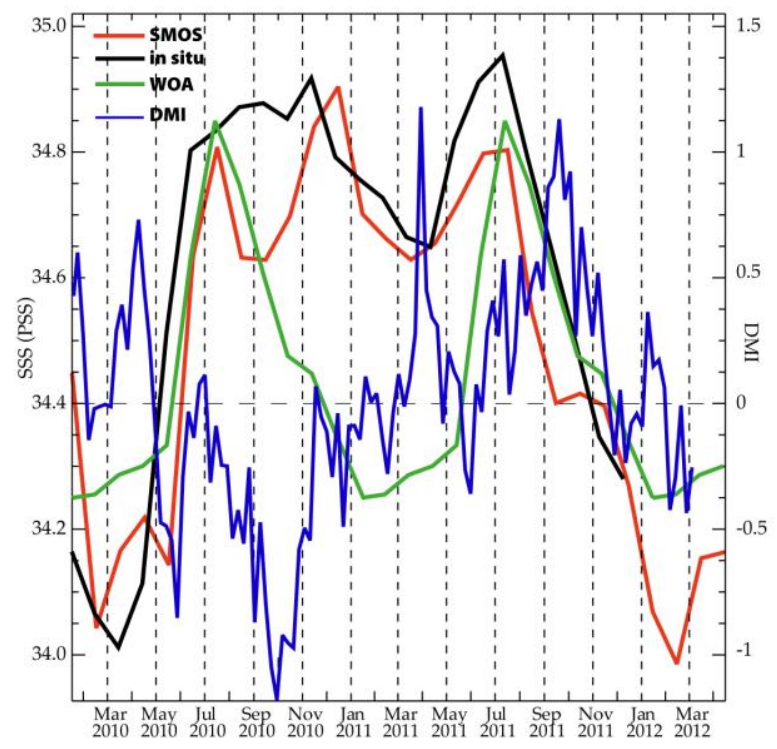

Figure 2. Time evolution of SMOS SSS (red), in situ SSS (black) and WOA05 climatology SSS (green), over the 1/2010 - 4/2012 period, averaged over the CIO box. The in situ product stops in December 2011. The blue curve features the evolution of Dipole Mode Index (right axis). 

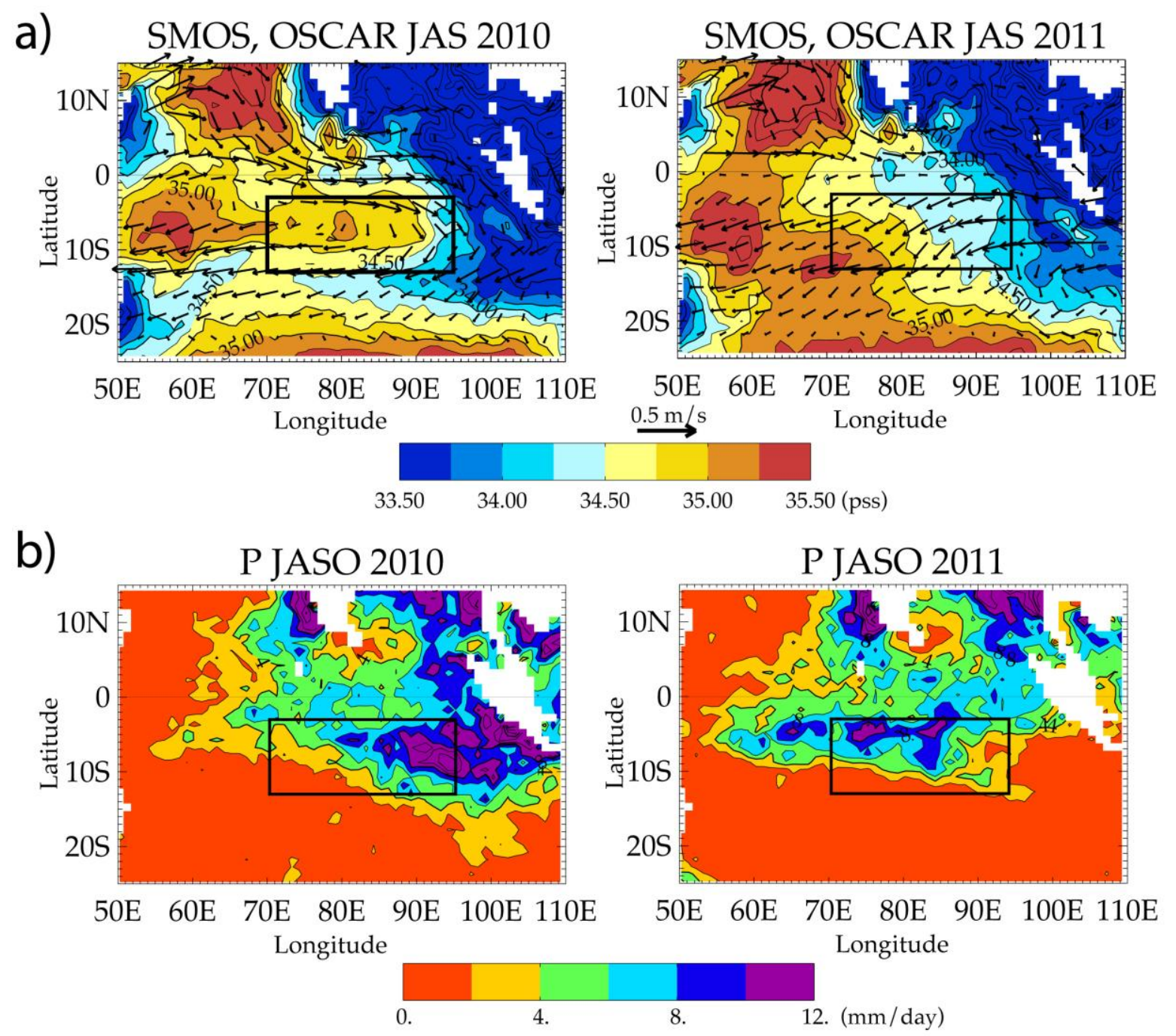

c)

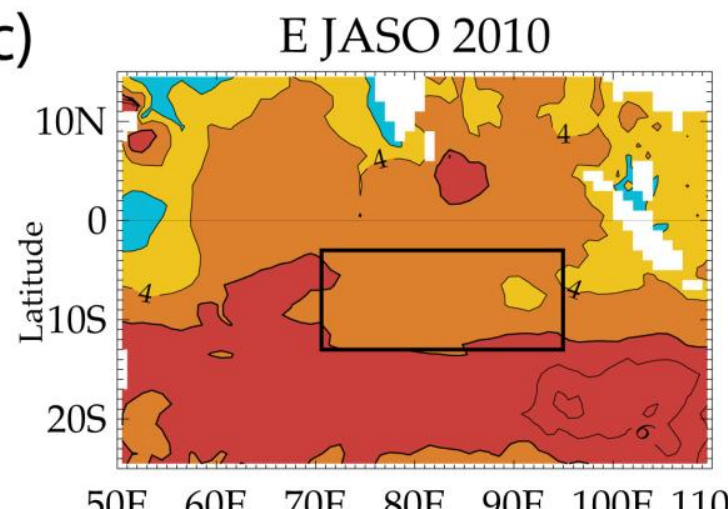

50E $\quad 60 \mathrm{E} \quad 70 \mathrm{E} \quad 80 \mathrm{E} \quad 90 \mathrm{E} \quad 100 \mathrm{E} \quad 110 \mathrm{E}$ Longitude

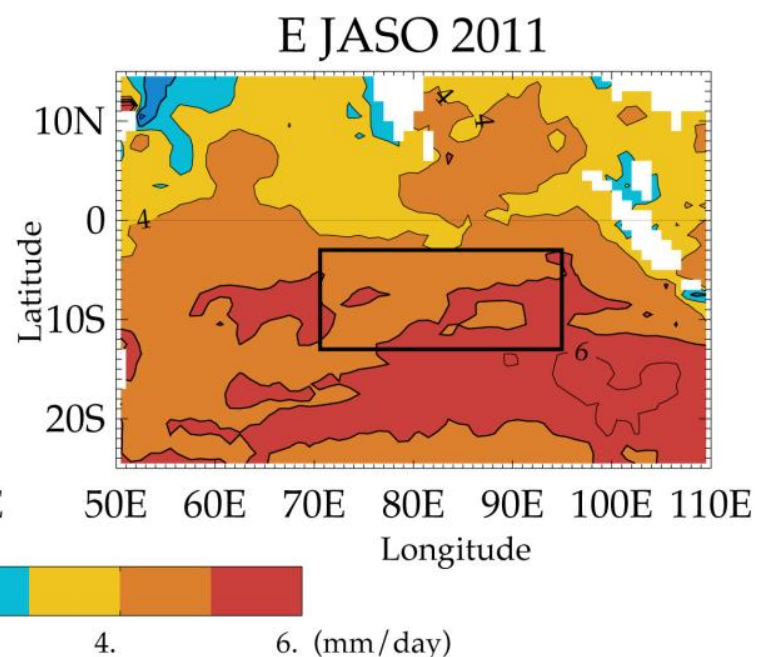

Figure 3. (a) SMOS SSS (contours) and OSCAR surface current (vectors) averaged during JulySeptember 2010 (left) and during July-September 2011(right). Isocontours are every 0.25 pss. (b) TMI precipitation averaged during July-October 2010 (left) and during July-October 2011 (right). Isocontours are every $2 \mathrm{~mm} /$ day. (c) Same as (b), for OAFLUX evaporation. Isocontours are every $1 \mathrm{~mm} /$ day. The black box shows the limits of the CIO box. The white areas correspond to the landmasses. 


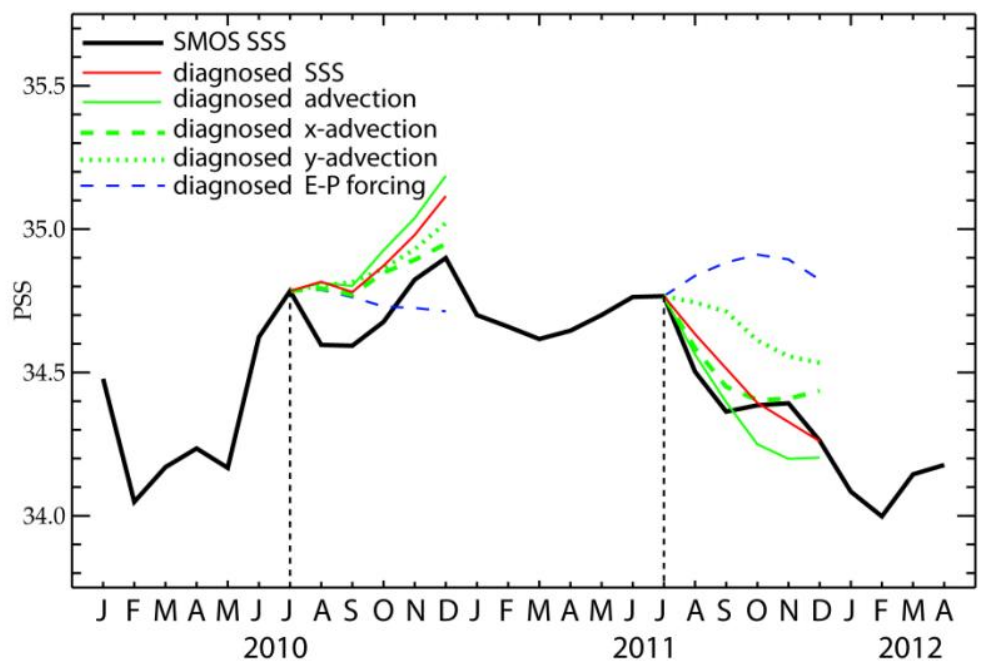

Figure 4. Time evolution of SMOS SSS (black) averaged over the CIO box. The coloured lines show the results of two 6-month long integrations of the anomalies of SSS tendency terms we diagnosed, starting in July 2010 and in July 2011. The anomalies are defined as departure from the 2004-2011 long-term mean. The effect of freshwater fluxes (evaporation minus precipitation) is in blue dashed. The effect of zonal advection is in green dashes. The effect of meridional advection is in green dots. Their sum (total advection) is in solid green. The sum of all terms (advection plus freshwater fluxes) is in red. 


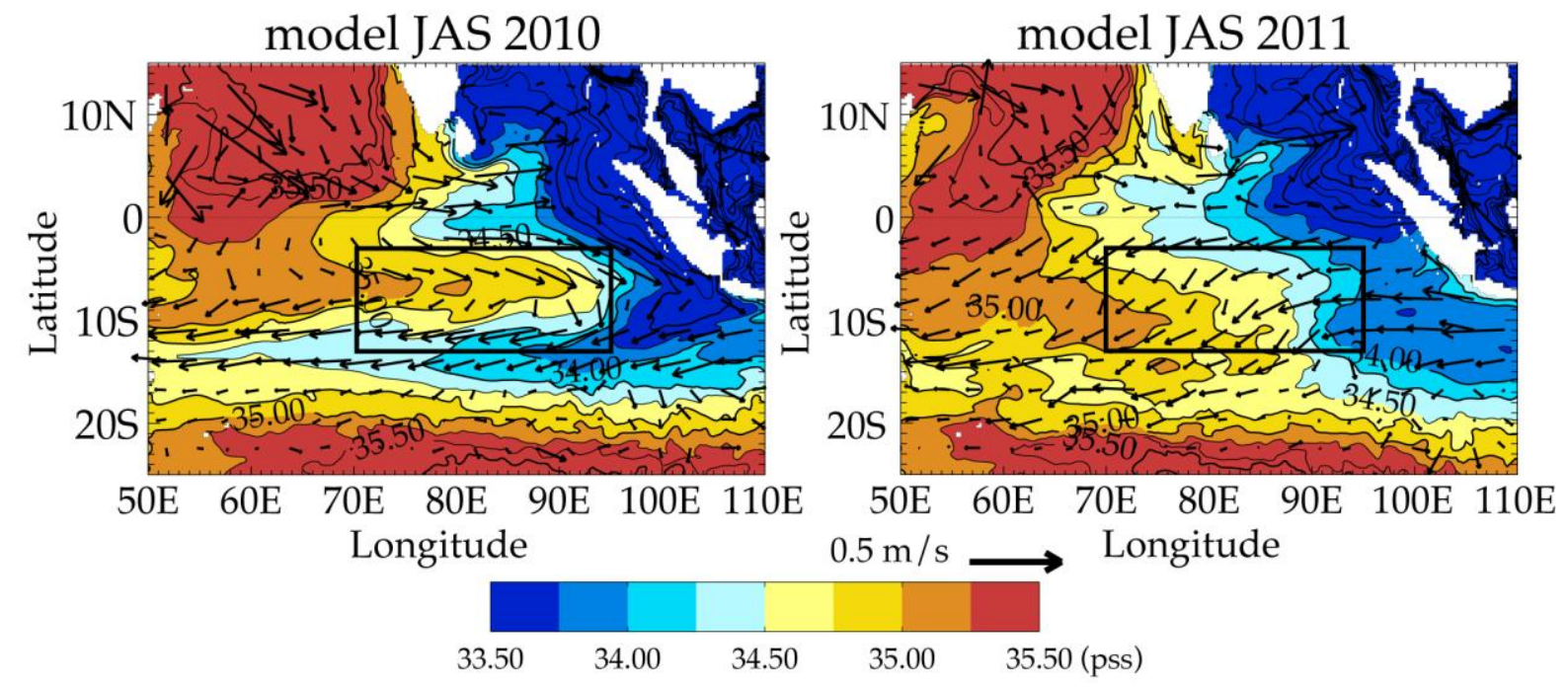

Figure 5. Model SSS (contours) and surface current (vectors) averaged during July-September 2010 (left) and during July-September 2011(right). Isocontours are every 0.25 pss 


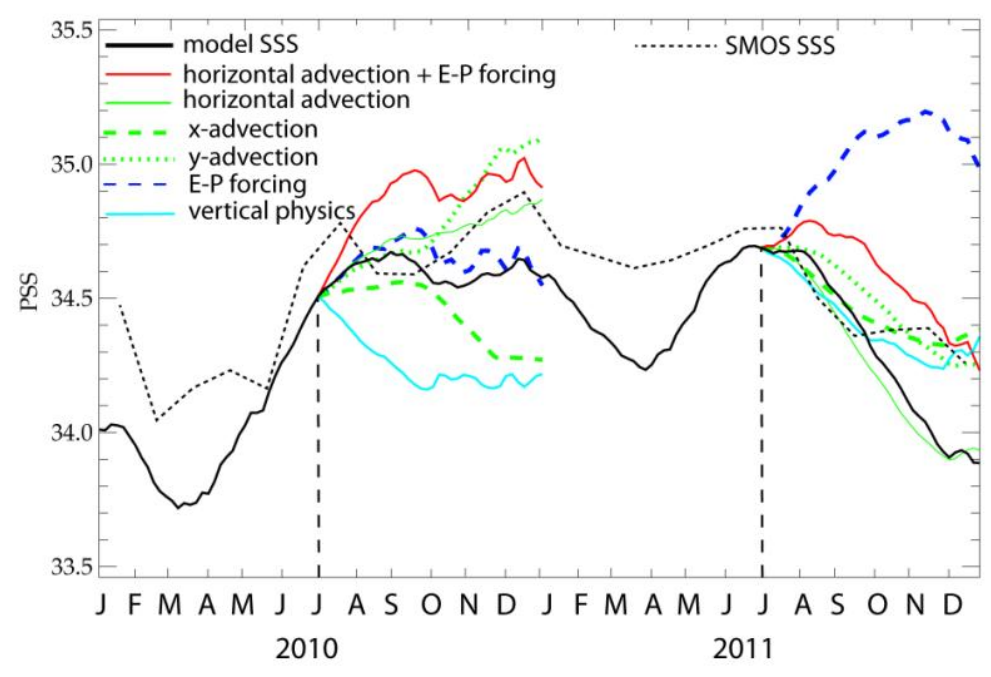

Figure 6. Same as Figure 4, for the model. The black curve is the salinity of the mixed-layer. The other curves feature the contribution of the various terms of the mixed-layer salinity evolution (see the text for details). For comparison, the SMOS SSS evolution of Figure 4 is added as dotted line. 